BMJ Open Ophthalmology

\section{Iridoplasty for plateau iris syndrome: a systematic review}

To cite: Bourdon $\mathrm{H}$, Aragno $\mathrm{V}$, Baudouin C, et al. Iridoplasty for plateau iris syndrome: a systematic review. BMJ Open Ophthalmology 2019;4:e000340. doi:10.1136/ bmjophth-2019-000340

- Additional material is published online only. To view please visit the journal online (http://dx.doi.org/10.1136/ bmjophth-2019-000340).

Received 21 May 2019

Revised 17 August 2019

Accepted 29 August 2019
Check for updates

(C) Author(s) (or their employer(s)) 2019. Re-use permitted under CC BY-NC. No commercial re-use. See rights and permissions. Published by BMJ.

${ }^{1} \mathrm{III}$, CHNO, Paris, France ${ }^{2}$ Ophthalmology, Hopital Ambroise-Pare, BoulogneBillancourt, France ${ }^{3}$ INSERM-DGOS Clinical Investigation Center (CIC) 1423, CHNO, Paris, France

Correspondence to Professor Antoine Labbé; dr. antoinelabbe@gmail.com

\section{ABSTRACT}

Plateau iris syndrome (PIS) is a frequent cause of angle closure. Argon laser peripheral iridoplasty (ALPI) has been proposed in PIS to widen the iridocorneal angle. The objective of the present study was to perform a systematic review of the available studies evaluating the efficacy of ALPI on intraocular pressure (IOP), iridocorneal angle opening and the number of medications in patients with chronic angle-closure associated with PIS. One prospective and seven retrospective studies with a minimum 1 month of follow-up were included. Although ALPI seemed to lower IOP, to decrease the number of topical antiglaucoma medications and widen the iridocorneal angle shortly after the procedure, there is no current evidence of long-term efficacy. To date, there is no robust scientific evidence to advocate ALPI as a treatment for chronic angle-closure caused by PIS.

\section{INTRODUCTION}

Of the nearly 67 million patients with glaucoma worldwide, primary angle-closure glaucoma (PACG) is a major cause of blindness, and it is estimated that 5.3 million people will suffer from blindness secondary to PACG in 2021. ${ }^{1}$ Relative pupillary block is considered to be the primary mechanism for angle closure, making laser peripheral iridotomy (LPI) a treatment of choice in PACG. LPI is able to significantly increase angle width and to lower intraocular pressure (IOP) in people with narrow angles. ${ }^{2}{ }^{3}$ However, several studies reported patients with persistent angle closure after LPI (around $58 \%-80 \%$ of cases) in which the most common underlying mechanism was plateau iris. ${ }^{24}$

Tornquist $e t a \tilde{l}$ first described the plateau iris configuration in 1958 on a young woman with high IOP and a flat iris surface. Gonioscopic examination revealed a closed-angle with a double-hump iris. Then plateau iris was classified by Wand $e t a l^{6}$ in 1977, differentiating 'plateau iris syndrome' from 'plateau iris configuration'. The 'configuration' refers to a preoperative condition with a gonioscopically confirmed narrow-angle and a flat iris. In most cases, the narrow angle associated with the plateau iris configuration was opened by a peripheral iridotomy. 'Plateau iris syndrome' (PIS) refers to a persistently narrow angle capable of closure despite a patent iridotomy resolving the associated relative pupillary block component. Wand et al confirmed and illustrated their observations in 1993 with histological and ultrasound biomicroscopy (UBM) exploration, showing an anteriorly displaced ciliary body that may secondarily rotate and push forward the peripheral iris root into the trabecular meshwork, causing angle narrowing or closure with a flat iris. As a consequence, PIS is now regarded as one of the mechanisms of angle-closure glaucoma. ${ }^{8}$

In 1982, after observing angle widening in front of an iridotomy site, Ritch ${ }^{9}$ proposed repeated non-transfixing spots on the iris periphery, describing the first argon laser peripheral iridoplasty (ALPI). ALPI contracts the peripheral iris tissues, pulling the iris away from the trabecular meshwork and reducing the area of iris-trabecular contact. Although ALPI is still considered as a laser treatment for PIS management, since 1982 and the first ALPI description, only a few studies have been conducted on this technique for PIS management.

The purpose of this study was to evaluate the efficacy and safety of ALPI on IOP lowering, angle opening and the number of medications in PIS by reviewing the available published literature.

\section{PATIENTS AND METHODS}

We conducted a systematic review of studies evaluating the efficacy of ALPI in PIS. The published literature was searched using the following keywords: ("Plateau iris" AND "Laser iridoplasty") OR ("Plateau iris" AND "Gonioplasty") OR "Iridoplasty". We analysed all the prospective and retrospective cohorts evaluating ALPI in documented chronic ACG caused by PIS. We included studies that evaluated IOP lowering, angle opening and/or the number of medications with a 1-month minimum follow-up. A total of 41 articles were analysed of which 33 were excluded (figure 1). The reasons for exclusion are detailed in online supplementary annex 1. We provided an individual and an 


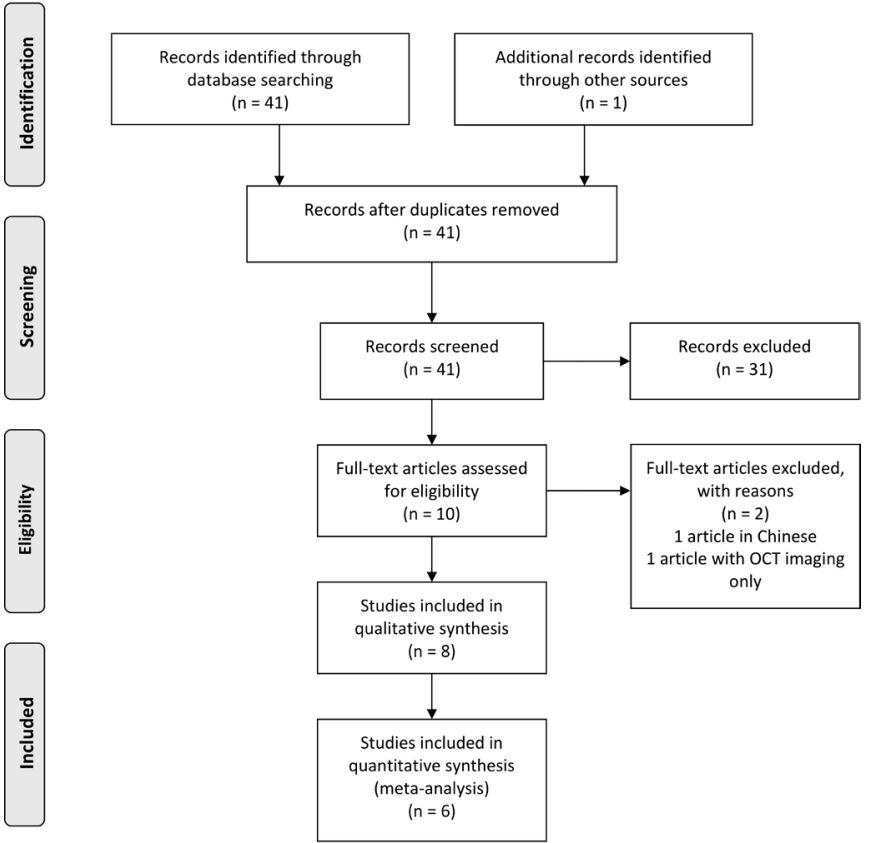

Figure 1 Flow chart.

overall analysis for 1-year and 6-year outcomes. Weighted mean IOP $\left(\mathrm{WM}_{\mathrm{IOP}}\right)$ was calculated for 1-year and 6-year outcomes using each study's final IOP weighted by the number of eyes included in the final evaluation:

$$
\mathrm{t} !
$$

\section{RESULTS}

To date, there have been no randomised controlled trials evaluating the use of iridoplasty in chronic angle-closure caused by PIS. We included seven retrospective case series $^{49-15}$ and one prospective observational casecontrol study ${ }^{16}$ published between 2004 and 2017. The study characteristics are described in table 1 . A total of 170 eyes of 147 patients were analysed. The eight studies were conducted on patients with chronic angle-closure persistent after laser peripheral iridotomy. Three studies included both PIS and lens-induced angle closure ${ }^{11} 1316$ and five evaluated PIS only. ${ }^{410-1517}$ One study provided a 1-month follow-up, ${ }^{15}$ five studies a 12-month follow-up, ${ }^{11-13} 16$ two studies had a long-term follow-up of more than 6 years ${ }^{417}$ and the longest one provided 92.4 months of mean follow-up. ${ }^{10}$

The ALPI procedure was not standardised and differed slightly between studies: spot sizes varied from 200 to $500 \mu \mathrm{m}$, energy levels from 200 to $550 \mathrm{~mW}$ and exposure times from 100 to $500 \mathrm{~ms}$ (table 2). The number of spots was specified in four studies and varied from 20 to $50 .{ }^{1014-16}$ The procedures were performed in one session, except for Ouazzani et al, ${ }^{15}$ who performed ALPI in two sessions, with or without a contact lens to put non-overlapping spots on $360^{\circ}$ of the peripheral iris. The primary efficacy outcome was a clear iris contraction for each laser application in all the studies presented. All procedures included postoperative steroidal or non-steroidal anti-inflammatory drugs and IOP control 45-60 min after the procedure.

\section{Individual study analyses}

Romito $e t a l^{10}$ conducted a retrospective non-controlled interventional case series with 53 ALPI procedures performed in 48 eyes of 28 patients with PIS confirmed by UBM. The mean follow-up was $92.4 \pm 26.5$ months. IOP varied from $15.92 \pm 2.62 \mathrm{~mm} \mathrm{Hg}$ at baseline to $14.35 \pm 2.19$ $\mathrm{mm} \mathrm{Hg}(\mathrm{p}>0.001)$ at the end of follow-up, with a non-significant augmentation in the number of medications from $0.81 \pm 0.94$ to $1.2 \pm 1.04$ ( $p>0.001)$. Five eyes required a repeated ALPI procedure $60.2 \pm 15.8$ months after the first one justified by a persistent appositional closure on dynamic gonioscopy. No filtration surgery was required, but $21 \%$ of the eyes underwent SLT and 10\% phacoemulsification warranted by a significant loss of vision caused by cataract.

Ritch $e t a l^{17}$ conducted a retrospective, non-controlled interventional case series with 26 ALPI procedures performed in 23 eyes of 14 patients with chronic angle-closure and PIS requiring pilocarpine or IOP-lowering drugs. The mean follow-up was $78.9 \pm 8.0$ months. IOP varied from $18.0 \pm 4.5 \mathrm{~mm} \mathrm{Hg}$ at baseline to $18.2 \pm 4.5 \mathrm{~mm} \mathrm{Hg}$ at the end of follow-up with a reduction in the number of medications from $1.2 \pm 1.0$ to $0.6 \pm 0.7$ (NS). The angle in 20 of $23(87.0 \%)$ eyes stayed open throughout the entire follow-up period after only one ALPI procedure. In three

\begin{tabular}{|c|c|c|c|c|c|c|}
\hline Author & Year & Study & Follow-up (months) & Patients & Eyes & Iridotomy \\
\hline Romito et $a l^{10}$ & 2019 & Retrospective & 92.3 & 28 & 48 & Prior \\
\hline Ritch $^{9}$ & 2004 & Retrospective & 78.9 & 26 & 14 & Prior \\
\hline Peterson et $a l^{4}$ & 2017 & Retrospective & 76 & 22 & 22 & Prior \\
\hline Ramakrishnan et al ${ }^{16}$ & 2016 & Prospective & 12 & 16 & 8 & Prior \\
\hline Junqueira et $a l^{11}$ & 2014 & Retrospective & 11.4 & 27 & 41 & Prior \\
\hline Singh et $a l^{12}$ & 2018 & Retrospective & 12 & 8 & 12 & Prior \\
\hline Gomes Prado et $a l^{13}$ & 2014 & Retrospective & 11.8 & 13 & 21 & Prior \\
\hline Ouazzani et al ${ }^{15}$ & 2006 & Retrospective & 1 & 5 & 9 & Prior \\
\hline
\end{tabular}
eyes, there was a gradual angle narrowing 5-9 years after 


\begin{tabular}{|c|c|c|c|c|c|}
\hline Author & Spot size $(\mu \mathrm{m})$ & Power (mW) & Exposure time (ms) & Number of spots & Area $\left({ }^{\circ}\right)$ \\
\hline Romito et al ${ }^{10}$ & 300 & $300-500$ & $400-500$ & 24 & 360 \\
\hline Ritch $^{9}$ & 500 & 200 & 500 & ND & 360 \\
\hline Peterson et $a l^{4}$ & $250-500$ & $200-400$ & 200 & ND & 360 \\
\hline Ramakrishnan et al ${ }^{16}$ & $200-400$ & $300-500$ & $200-400$ & $20-24$ & 360 \\
\hline Junqueira et $a l^{11}$ & 500 & 250 & 500 & ND & 360 \\
\hline Singh et $a l^{12}$ & 450 & 550 & 100 & ND & 360 \\
\hline Gomes Prado et $a^{13}$ & ND & ND & ND & ND & ND \\
\hline Ouazzani et $a l^{15}$ & 300 & 500 & 300 & $20-50$ & 360 \\
\hline
\end{tabular}

ALPI, argon laser peripheral iridoplasty; ND, not done.

initial ALPI, but it was permanently reopened by a single differed treatment. No filtration surgery was necessary in any eye during follow-up.

Peterson $e t a t^{t}$ retrospectively reviewed 22 eyes of 22 patients who underwent ALPI for a persistent iridotrabecular apposition after LPI caused by PIS with a mean 76-month follow-up. The mean IOP was $21.3 \pm 7.1 \mathrm{~mm} \mathrm{Hg}$ before ALPI, $16.9 \pm 3.3$ after 1 year $(\mathrm{p}=0.012), 16.5 \pm 3.9$ $(\mathrm{p}=0.002)$ after 2 years, $17.2 \pm 4.2(\mathrm{p}=0.016)$ after 3 years, $16.6 \pm 2.7(\mathrm{p}=0.014)$ after 4 years, $18.3 \pm 3.2(\mathrm{p}=0.062)$ after 5 years and $19.7 \pm 6.4 \mathrm{mmHg}(\mathrm{p}=0.038)$ at the end of follow-up $(\mathrm{p}=0.38)$. Only two $(9 \%)$ eyes maintained an IOP $<21 \mathrm{~mm} \mathrm{Hg}$ without medications or surgery, and 17 eyes $(77 \%)$ underwent surgery an average of $49.1 \pm 7.9$ months after ALPI. Eight eyes $(36 \%)$ underwent filtering surgery and nine eyes $(41 \%)$ underwent phacoemulsification. Both results on IOP and the number of medications became non-significant between the fourth and fifth year of follow-up, and consequently, ALPI efficacy could not be ruled out with certainty.

Ramakrishnan et $a l^{16}$ conducted a prospective, observational case-control study with a 1-year follow-up. They included 16 eyes of 12 patients and among them 8 eyes had angle closure due to PIS and 8 had primary angle closure. All patients had a previous LPI without angle opening. When considering the entire population, there was a significant decrease in IOP from $24.4 \pm 5.6$ $\mathrm{mmHg}$ to $16.5 \pm 5.4 \mathrm{mmHg}(\mathrm{p}<0.001)$ at the end of follow-up. However, there was no specific analysis for patients with PIS in that study. Gonioscopic examination focused on peripheral anterior synechiae (PAS) that were reduced from 3.5 to 2.5 clock hours $(p<0.001)$. They also confirmed their observations with anterior-segment optical coherence tomography (AS-OCT) showing an angle opening depth (AOD500) increasing from $0.132 \pm 0.016$ at baseline to $0.179 \pm 0.062 \mathrm{~mm}(\mathrm{p}<0.001)$ at 1 year. The mean number of antiglaucoma medications decreased from $1.6 \pm 0.9$ to $0.7 \pm 1.1(\mathrm{p}<0.001)$. There was no subgroup analysis focusing on PIS only. This study was the only study reporting adverse events with $20 \%$ IOP spikes, $16 \%$ iris haemorrhages and $4 \%$ persistent intraocular inflammation at 1 week.
Junqueira $e a^{11}$ conducted a 1-year retrospective chart review of 27 patients who underwent ALPI for persistent occludable angles after laser peripheral iridotomy. The most common underlying mechanisms were plateau iris (56\%) followed by lens-induced angle closure (34\%). Considering the entire population, IOP was significantly reduced from $17.9 \pm 4.9 \mathrm{~mm} \mathrm{Hg}$ to $14.5 \pm 4.2 \mathrm{~mm} \mathrm{Hg}$ $(\mathrm{p}<0.01)$ at the end of follow-up, with no significant differences between patients with PIS and lens-induced angle closure $(\mathrm{p}=0.34)$. Approximately $90 \%$ of the eyes had a non-occludable angle defined as a posterior trabecular meshwork visible on $180^{\circ}$ without indentation on gonioscopic examination following ALPI. The number of medications was not evaluated in this study.

Singh et $a l^{12}$ conducted a retrospective review on 12 eyes of 8 patients with PIS confirmed by UBM, who required medical treatment and underwent ALPI with a 1-year follow-up. A statistically significant IOP reduction was found after 1 year from $20.6 \pm 4.8 \mathrm{~mm} \mathrm{Hg}$ to $17.8 \pm 3.8$ $\mathrm{mm} \mathrm{Hg}(\mathrm{p}=0.01)$. Angle widening was noted in $46 \%$ of the treated quadrants by at least one grade (Shaffer's classification) after 1 month of follow-up. There was no significant change in the number of medications.

In a 1-year retrospective study, Gomes Prado et $\mathrm{l}^{13}$ investigated 35 eyes of 21 patients: $56 \%$ of eyes were clinically diagnosed with PIS, 34\% had lens-induced angle closure and $10 \%$ had other causes of angle closure. Considering the entire population, IOP was significantly reduced from $18.2 \pm 4.7 \mathrm{~mm} \mathrm{Hg}$ to $14.6 \pm 3.8 \mathrm{~mm} \mathrm{Hg}(\mathrm{p}<0.01)$ with no significant difference between PIS and lens-induced subgroups. The value of this study was the absence of change in the treatment regimen during the entire follow-up with $1.5 \pm 1.1$ medications. After ALPI, $91 \%$ of the patients showed non-occludable angle in gonioscopy without specifications on the examination criteria.

Ouazzani et $a l^{15}$ investigated nine eyes of five patients who underwent ALPI for PIS with glaucoma diagnosed by dynamic gonioscopy. The mean IOP before ALPI was $21.1 \mathrm{~mm} \mathrm{Hg}$, which decreased to $14.4 \mathrm{~mm} \mathrm{Hg}$ at 1 month (no statistical analysis). After the procedure, hypotensive treatment could be withdrawn for four eyes. No data were collected on angle opening. 
Table 3 IOP and angle widening variations (IOP in $\mathrm{mm} \mathrm{Hg}$ )

\begin{tabular}{|c|c|c|c|c|c|}
\hline \multirow[b]{2}{*}{ Author } & \multirow[b]{2}{*}{ Baseline IOP $(\mathrm{mm} \mathrm{Hg})$} & \multirow[b]{2}{*}{ Last IOP $(\mathrm{mm} \mathrm{Hg})$} & \multicolumn{2}{|c|}{ IOP variation } & \multirow[b]{2}{*}{$P$ value } \\
\hline & & & Final value & Percentage & \\
\hline Romito et al (7.5 years) ${ }^{10}$ & $15.9 \pm 2.62$ & $14.3 \pm 2.18$ & -1.6 & $10 \%$ & NS \\
\hline Ritch $\left(6\right.$ years) ${ }^{9}$ & $18.0 \pm 4.5$ & $18.2 \pm 4.5$ & +0.2 & $1 \%$ & 0.38 \\
\hline Peterson et al (6 years) ${ }^{4}$ & $21.3 \pm 7.1$ & $18.3 \pm 3.2$ & -3.0 & $14 \%$ & ND \\
\hline Peterson et al (1 year) ${ }^{4}$ & $21.3 \pm 7.1$ & $16.9 \pm 3.3$ & -4.4 & $20 \%$ & 0.012 \\
\hline Ramakrishnan et al (1 year) ${ }^{16}$ & $24.4 \pm 5.6$ & $16.5 \pm 5.4$ & -7.9 & $32 \%$ & $<0.001$ \\
\hline Junqueira et al (1 year) $)^{11}$ & $17.9 \pm 4.9$ & $14.5 \pm 4.2$ & -3.4 & $19 \%$ & $<0.01$ \\
\hline Singh et al (1 year) ${ }^{12}$ & $20.6 \pm 4.8$ & $17.8 \pm 3.8$ & -2.8 & $13 \%$ & $<0.1$ \\
\hline Gomes Prado et al (1 year) ${ }^{13}$ & $18.2 \pm 4.7$ & $14.6 \pm 3.8$ & -3.6 & $20 \%$ & $<0.01$ \\
\hline Ouazzani et al (1 month) ${ }^{15}$ & 21.1 & 14.4 & -3.4 & $19 \%$ & ND \\
\hline
\end{tabular}

$\mathrm{n}$ years indicate follow-up time.

$\mathrm{IOP}$, intraocular pressure; ND, not done.

\section{Effect on IOP}

After ALPI, IOP decreased from $-6.7 \mathrm{~mm} \mathrm{Hg}(-30 \%)$ after 1 month $^{15}$ to $-2.8 \mathrm{~mm} \mathrm{Hg}(-19 \%)(\mathrm{p}=0.01),{ }^{12}-3.4 \mathrm{~mm} \mathrm{Hg}$ $(-19 \%)(\mathrm{p}<0.01),{ }^{11}-3.6 \mathrm{mmHg}(-20 \%)(\mathrm{p}<0.01),{ }^{13}-4.4$ $(-21 \%)(\mathrm{p}=0.012)^{4}$ and $-7.9 \mathrm{~mm} \mathrm{Hg}(-32 \%)(\mathrm{p}<0.001)^{16}$ after 1 year. After a mean follow-up of 6 years, Ritch $e t$ $a l^{17}$ did not find any significant IOP change as compared with baseline $(+0.2 \mathrm{~mm} \mathrm{Hg})$, similar to Peterson et al, ${ }^{4}$ who found a $-1.6 \mathrm{~mm} \mathrm{Hg}$ ( $\mathrm{p}=0.38)$ non-significant IOP variation. Moreover, in this study, $36 \%$ eyes underwent filtering surgery and $41 \%$ eyes phacoemulsification. After 7.5 years of follow-up, Romito et $\mathrm{l}^{10}$ found a $-1.56 \mathrm{~mm} \mathrm{Hg}$ $(-10 \%)(p>0.01)$ variation. IOP changes are presented in table 3 .

In studies with at least 1 year of follow-up, weighted IOP decreased from $19.6 \mathrm{~mm} \mathrm{Hg}$ at baseline to $15.6 \mathrm{~mm} \mathrm{Hg}$ at the last visit after ALPI, providing a $-4.0 \mathrm{~mm} \mathrm{Hg}$ or $-20 \%$ IOP variation. ${ }^{411-1316}$ In the studies with a 6-year follow-up, weighted mean IOP varied from $18.7 \mathrm{~mm} \mathrm{Hg}$ to $18.5 \mathrm{~mm} \mathrm{Hg}$ at the last visit after ALPI, providing a -0.2 mm Hg or $1 \%$ variation $^{417}$ (figure 2 ).

\section{Effects on angle widening}

Iridocorneal angle changes after ALPI were evaluated with gonioscopy in seven studies. Initial PIS evaluation was confirmed by UBM in four studies ${ }^{41011} 16$ and AS-OCT in one study. ${ }^{16}$ The final angle evaluation was

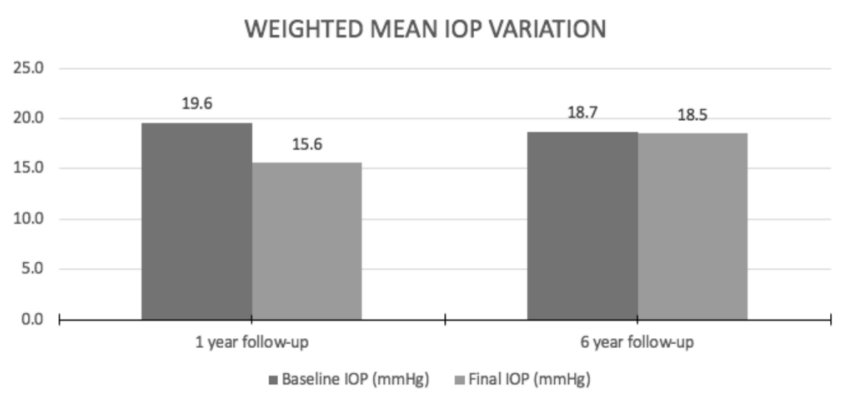

Figure 2 Weighted mean IOP variation (IOP, intraocular pressure; $n$ year, indicate follow-up time). done by gonioscopy except for one study reported by Ramashrikan et $a^{16}$ who added AS-OCT evaluation. Laser efficacy was most often characterised by the gain of 1 Shaffer or Spaeth grade in two of four quadrants after the laser procedure. Ritch $e t a l^{17}$ had successful procedures in $100 \%$ of eyes with at least Shaffer II angle opening after the laser procedure, and $13 \%$ of the eyes had progressive angle narrowing within 5-9 years, requiring a second deferred ALPI procedure that was successful in all cases. Romito $e t a l^{10}$ observed no unsuccessful ALPI procedures but noted a recurrent iridocorneal apposition in five eyes requiring a new successful ALPI procedure performed $60.2 \pm 15.8$ months after the initial treatment. Peterson $e t$ $a l^{4}$ had an $87 \%$ direct success rate and $13 \%$ of the eyes needed a direct second procedure to gain 1 Shaffer grade, and $18 \%$ needed a new procedure after gradual angle narrowing. Singh $e t a l^{12}$ had the lowest success rate with $46 \%$ of patients with angle widening. Junqueira et $a l^{11}$ found a posterior trabecular meshwork visible on $180^{\circ}$ without indentation on gonioscopic examination for $90 \%$ of eyes after the laser procedure. Ramakrishnan $e t a l^{16}$ were the only authors to focus on PAS, reducing the median number of clock hours with PAS from 3.75 (2.00 $6.50)$ to $2.50(0.75-5.00)(\mathrm{p}<0.001)$. AS-OCT evaluation also found an angle-opening distance at $500 \mu \mathrm{m}$ from the scleral spur (AOD500) increased from $0.132 \pm 0.016$ at baseline to $0.179 \pm 0.062 \mathrm{~mm}(\mathrm{p}<0.001)$ after 1 year. Gomes Prado $\mathrm{et}_{\mathrm{al}} \mathrm{l}^{3}$ declared $91 \%$ non-occludable angle after the ALPI procedure with no further details provided. The changes in angle widening are presented in table 4.

\section{Effect on the number of antiglaucoma medications}

The number of medications was not systematically evaluated in the publications that evaluated ALPI efficacy. Ouazzani $e t a l^{5}$ stopped medications in four of the nine eyes studied after 1 month. Gomes Prado $e t a l^{13}$ kept the same treatment regimen during the follow-up in order to analyse the efficacy of ALPI without the bias of hypotensive medication changes. Ramakrishnan $e t a l^{16}$ showed a significant reduction from $1.6 \pm 0.5$ to $0.7 \pm 1$ medications 


\begin{tabular}{|c|c|c|}
\hline Author & Angle widening & Number of medications \\
\hline Romito et $a l^{10}$ & ND & $\begin{array}{l}0.81 \pm 0.94 \text { to } 1.2 \pm 1.04 \\
(p>0.001)\end{array}$ \\
\hline Ritch $^{9}$ & $100 \%$ & $\begin{array}{l}1.2 \pm 1.0 \text { to } 0.6 \pm 0.7 \text { (no } \\
p \text { value) }\end{array}$ \\
\hline Peterson et $a l^{4}$ & $71 \%$ & $\begin{array}{l}0.41 \pm 0.67 \\
\text { To } 0.81 \pm 0.83 \\
(p=0.056)(1 \text { year }) \\
\text { To } 1.67 \pm 1.03 \\
(p=0.44) \text { (5 years) }\end{array}$ \\
\hline Ramakrishnan et al ${ }^{16}$ & NA & $\begin{array}{l}1.6 \pm 0.5 \text { to } 0.7 \pm 1 \\
(p<0.001)\end{array}$ \\
\hline Junqueira et $a l^{11}$ & $90 \%$ & ND \\
\hline Singh et al ${ }^{12}$ & $46 \%$ & Non-significant \\
\hline Gomes Prado et $a l^{13}$ & $91 \%$ & $\begin{array}{l}\text { Treatment regimen } \\
\text { was not changed }\end{array}$ \\
\hline Ouazzani et al ${ }^{15}$ & ND & $\begin{array}{l}\text { Four eyes stopped } \\
\text { medications }\end{array}$ \\
\hline
\end{tabular}

$\mathrm{n}$ years indicate follow-up time.

NA, not applicable; ND, not done.

$(\mathrm{p}<0.001)$ after 1 year. Ritch et $a l^{17}$ showed no significant changes in antiglaucoma medications with no filtration surgery required after more than 6 years. Romito et $a l^{10}$ found no significant change in the number of medications (from $0.81 \pm 0.94$ to $1.2 \pm 1.04 ; \mathrm{p}>0.05$ ) after 7.5 years and 10 eyes required a selective laser trabeculoplasty (SLT) procedure. Peterson et $a l^{t}$ was the only study showing a significant increase in the number of medications 2 years after ALPI and the need for filtering surgery or phacoemulsification in two-thirds of the eyes. The effects on the number of antiglaucoma medications are presented in table 4 .

\section{DISCUSSION}

PIS is a common cause of chronic angle-closure glaucoma, and ALPI is presented by some authors as a safe and non-invasive procedure for IOP control and angle opening. Our study is the first review evaluating the efficacy of ALPI in PIS since $\mathrm{Ng}$ et $a l^{18}$ published a Cochrane meta-analysis in 2012 demonstrating the lack of clinical outcomes on ALPI. At that time, only the Ritch $e t$ $a l^{17}$ retrospective cohort study published in 2004 was available. Seven years later, there is still no randomised control trial published on ALPI efficacy and safety on chronic angle-closure caused by PIS. Unfortunately, the recent cohort studies contribute little, non-standardised information with results often combining PIS and lens-induced angle closure, ${ }^{11} 1316$ that in 2019 does not allow us to draw a firm conclusion on the role of ALPI in PIS.

The first ALPI procedures were proposed by Ritch ${ }^{9}$ in 1982 to treat medically unresponsive angle-closure attack. Their observations were based on angle-closure glaucoma without distinguishing the underlying mechanisms. The aim of ALPI was to contract iris peripheral stroma to decrease its contact with the trabecular meshwork. These iris changes following ALPI were confirmed histopathologically in 1993 in a case report. Sassani $e t a l^{19}$ theorised that heat-induced shrinkage of collagen may be responsible for the short-term response to ALPI and that the healing characterised by the contraction of the fibroblastic membrane may promote long-term angle opening. Ritch $e t a l^{20}$ then extended ALPI indications to PIS, explaining that an anteriorly positioned ciliary body pushing the iris root forward towards the trabecular meshwork could be flattened by lower power, longer duration and large laser spot sizes, causing deep contraction burns. Iridocorneal angle morphology change before and after ALPI was evaluated with AS-OCT by Lim et al on 60 eyes with persistent occludable angle after LPI regardless of the angle-closure mechanism. Using the Anterior Segment Analysis Program, a significant increase in iridocorneal angle parameters was found: angle opening distance (AOD500 and AOD750), trabecular iris surface area (TISA500 and TISA750), anterior chamber volume and anterior chamber area (ARA500 and ARA750). However, no significant changes were observed on central anterior chamber parameters: anterior chamber width, anterior chamber depth and lens vault, illustrating the action of ALPI on the peripheral iridocorneal angle morphology.

The spot sizes might explain the disappointing results found by Peterson $e t a l^{4}$ and Singh $e t a l,{ }^{12}$ given that they used smaller spots and a shorter exposure time than Ritch et $a l^{17}$ and Romito et $a l^{10}$ Nevertheless, these authors explained their laser protocols as preventing adverse events. Ramakrishnan et $a l^{16}$ were the only authors to show transient photophobia following an ALPI procedure, and no other adverse events were reported in the other published studies on PIS. Espana $e t a l^{21}$ presented a series of 12 eyes in eight patients with persistent iris dilatation after an ALPI procedure for acute angle-closure. Only one patient had a decrease in visual acuity, but seven of the eight patients declared blurred vision. The pupillary response to pilocarpine instillation was minimal or absent and mydriasis eventually resolved in all eyes without treatment within 1 year. The reversibility of these complications should reassure the patients and the ophthalmologist on ALPI tolerance. Moreover, in the study reported by Espana, ALPI was performed for an acute angle-closure that could be by itself responsible for persistent iris dilation.

Despite non-significant long-term results, Peterson et $a l^{4}$ compared their results to the Ritch $e t a l^{17}$ cohort. They noted a higher baseline IOP (mean IOP, $21.3 \mathrm{~mm} \mathrm{Hg}$ ) with fewer eyes on IOP-lowering medications (seven eyes, $33 \%$, on one to two medications) in the Peterson's cohort, compared with Ritch's study (mean IOP, $18 \mathrm{~mm} \mathrm{Hg}$ with $100 \%$ of eyes on IOP-lowering medication). In addition, seven eyes (33\%) in Peterson's study had peripheral anterior synechiae (PAS), and two eyes $(9 \%)$ had glaucomatous damage before ALPI, whereas PAS were not documented, and no eyes had glaucomatous damage in the Ritch $e t a l$ study. It is noteworthy that 
Peterson's cohort had more advanced disease than the patients from the Ritch et al study.

Based on Ouazzani et als observations, ${ }^{15}$ iridoplasty seems to have a rapid effect on lowering IOP, which seems maintained after 1 year. To date, Gomes Prado et $a l^{13}$ is the only study excluding hypotensive medication bias with no change in treatment during the 11.8 months of follow-up. However, long-term IOP management seems more difficult. Ritch showed three eyes (13\%) with gradual angle narrowing 5-9 years after initial ALPI, but the angle reopened after a second ALPI treatment. Romito et $a l^{10}$ declared five eyes $(10 \%)$ requiring a new ALPI for gradual angle reclosure 60.2 months after the first procedure. The author attributed this angle closure to the gradual lens growth and every secondary procedure was successful. Six eyes (10\%) also required phacoemulsification justified by significant loss of vision. Peterson et al's management of angle narrowing was different with eight $(36 \%)$ eyes requiring filtering surgery and nine $(41 \%)$ eyes requiring phacoemulsification within 6 years of follow-up. All eyes had controlled IOP after cataract extraction, and five out of nine eyes were free of IOP-lowering medications 3 months after surgery. Cataract surgery attenuated anterior positioning of the ciliary processes in eyes with primary angle-closure, concomitant with significant opening of the angle. ${ }^{22}$ However, Viet Tran $e t a l^{23}$ showed the persistence of iridociliary apposition after phacoemulsification in a series of six patients with PIS previously treated with LPI and ALPI. These studies show the low probability of IOP resolution after phacoemulsification as a standalone procedure in PIS.

The ciliary bodies' anteposition is the initial cause of angle-closure physiopathology in PIS. However, the ALPI mechanism is only based on the thinning of the superficial iris tissue at the level of the crowded angle ${ }^{24}$ and has no impact on the ciliary body anteposition, which might explain the poor long-term outcomes. Hollander et $a t^{25}$ hypothesised that shrinking the ciliary processes with endoscopic cyclophotocoagulation (ECP) creates a space that will accommodate the thickened peripheral iris during pupillary dilation and prevent angle closure. In a series of nine eyes of six patients with PIS, they showed a significant IOP reduction from $25.2 \mathrm{~mm} \mathrm{Hg}$ to 17.1 $\mathrm{mm} \mathrm{Hg}(\mathrm{p}<0.05)$ with a lowering in the number of medications after a 73-month follow-up. Moreover, the angles were opened in UBM only in areas treated with ECP with corresponding flattened ciliary processes. This invasive procedure could become an advantageous treatment for patients with PIS and a persistent occludable angle or uncontrolled IOP due to PIS.

\section{CONCLUSION}

ALPI does lower IOP in chronic angle-closure PIS over the short term and may widen the iridocorneal angle. These effects may be associated with a short-term reduction in the number of medications. Nevertheless, these observations are based on small retrospective cohort studies with a 1-year follow-up and there is no current evidence of long-term efficacy among the three long-term cohort studies available. Moreover, the effects of ALPI on visual field progression have never been studied. As a consequence, there is no strong scientific evidence as yet to advocate ALPI as a treatment of chronic angle-closure caused by PIS.

Contributors VA and $\mathrm{HB}$ were in charge of bibliography, data extraction and article redaction. $A L$ and $C B$, providing their glaucoma expertise, were in charge of the article supervision and careful rereading.

Funding The authors have not declared a specific grant for this research from any funding agency in the public, commercial or not-for-profit sectors.

Competing interests None declared.

Patient consent for publication Not required.

Provenance and peer review Not commissioned; externally peer reviewed.

Open access This is an open access article distributed in accordance with the Creative Commons Attribution Non Commercial (CC BY-NC 4.0) license, which permits others to distribute, remix, adapt, build upon this work non-commercially, and license their derivative works on different terms, provided the original work is properly cited, appropriate credit is given, any changes made indicated, and the use is non-commercial. See: http://creativecommons.org/licenses/by-nc/4.0/.

\section{REFERENCES}

1. Tham Y-C, Li X, Wong TY, et al. Global prevalence of glaucoma and projections of glaucoma burden through 2040: a systematic review and meta-analysis. Ophthalmology 2014;121:2081-90.

2. He M, Friedman DS, Ge J, et al. Laser peripheral iridotomy in primary angle-closure suspects: biometric and gonioscopic outcomes. Ophthalmology 2007;114:494-500.

3. Thomas R, Arun T, Muliyil J, et al. Outcome of laser peripheral iridotomy in chronic primary angle closure glaucoma. Ophthalmic Surg Lasers 1999;30:547-53.

4. Peterson JR, Anderson JW, Blieden LS, et al. Long-Term outcome of argon laser peripheral iridoplasty in the management of plateau iris syndrome eyes. J Glaucoma 2017;26:780-6.

5. Törnquist R. Angle-Closure glaucoma in an eye with a plateau type of iris. Acta Ophthalmol 1958;36:419-23.

6. Wand M, Grant WM, Simmons RJ, et al. Plateau iris syndrome. Trans Sect Ophthalmol Am Acad Ophthalmol Otolaryngol 1977;83:122-30.

7. Wand M, Pavlin CJ, Foster FS. Plateau iris syndrome: ultrasound biomicroscopic and histologic study. Ophthalmic Surg 1993;24:129-31.

8. American Academy of Ophthalmology. Angle-closure glaucoma. In: Basic and clinical science course: glaucoma. San Francisco: American Academy of Ophthalmology, 2012: 2004-5.

9. Ritch R. Argon laser treatment for medically unresponsive attacks of angle-closure glaucoma. Am J Ophthalmol 1982;94:197-204.

10. Romito N, Bluwol E, Graber M, et al. Argon laser iridoplasty for plateau iris syndrome: long-term outcomes of 48 eyes. J Glaucoma 2019.

11. Junqueira DLM, Prado VG, Lopes FS, et al. Non-pupillary block angle-closure mechanisms: a comprehensive analysis of their prevalence and treatment outcomes. Arq Bras Oftalmol 2014;77:360-3.

12. Singh N, Pegu J, Dubey S, et al. To study the efficacy of laser peripheral iridoplasty in the treatment of eyes with primary angle closure and plateau iris syndrome, unresponsive to laser peripheral iridotomy, using OCT as a tool: Comment. J Glaucoma 2017;26:e123.

13. Gomes Prado V, Dorairaj S, Biteli LG, et al. Role of laser iridoplasty in the management of angle closure mechanisms other than pupillary block. JOCGP 2014;8:82-4.

14. Lim DK, Chan HW, Zheng C, et al. Quantitative assessment of changes in anterior segment morphology after argon laser peripheral iridoplasty: findings from the EARL Study Group. Clin Experiment Ophthalmol 2019;47:33-40.

15. Ouazzani BT, Berkani M, Ecoffet M, et al. [Argon laser iridoplasty in the treatment of angle closure glaucoma with plateau iris syndrome] J Fr Ophtalmol 2006;29:625-8.

16. Ramakrishnan R, Mitra A, Abdul Kader M, et al. To study the efficacy of laser peripheral iridoplasty in the treatment of eyes with primary angle closure and plateau iris syndrome, unresponsive 
to laser peripheral iridotomy, using Segment OCT as a tool. $J$ Glaucoma 2016;25:440-6.

17. Ritch R, Tham CCY, Lam DSC. Long-Term success of argon laser peripheral iridoplasty in the management of plateau iris syndrome. Ophthalmology 2004;111:104-8.

18. WSN, Ang GS, Azuara-Blanco A. Laser peripheral iridoplasty for angle-closure. Cochrane Database Syst Rev 2012;2.

19. Sassani JW, Ritch R, McCormick S, et al. Histopathology of argon laser peripheral iridoplasty. Ophthalmic Surg 1993;24:740-5.

20. Ritch R, Tham CCY, Lam DSC. Argon laser peripheral iridoplasty (ALPi): an update. Surv Ophthalmol 2007;52:279-88.

21. Espana EM, Ioannidis A, Tello C, et al. Urrets-Zavalia syndrome as a complication of argon laser peripheral iridoplasty. $\mathrm{Br} \mathrm{J}$ Ophthalmol 2007;91:427-9.
22. Nonaka A, Kondo T, Kikuchi M, et al. Angle widening and alteration of ciliary process configuration after cataract surgery for primary angle closure. Ophthalmology 2006;113:437-41.

23. Viet Tran H, Liebmann JM, Ritch R. Iridociliary apposition in plateau iris syndrome persists after cataract extraction. Am J Ophthalmol 2003; $135: 40-3$.

24. Liu J, Lamba T, Belyea DA. Peripheral laser iridoplasty opens angle in plateau iris by thinning the cross-sectional tissues. Clin Ophthalmol 2013;7:1895-7.

25. Hollander DA, Pennesi ME, Alvarado JA. Management of plateau iris syndrome with cataract extraction and endoscopic cyclophotocoagulation. Exp Eye Res 2017;158:190-4. 